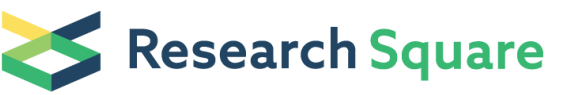 \\ Preprints are preliminary reports that have not undergone peer review. \\ They should not be considered conclusive, used to inform clinical practice, or referenced by the media as validated information.
}

\section{Association of MTHFR rs1801133 and Homocysteine With Legg-Calvé-Perthes Disease in Mexican Patients}

José Guillermo Buendía Pazarán

Escuela Nacional de Ciencias Biologicas Departamento de Morfologia

Edgar Hernández Zamora

Instituto Nacional de Rehabilitacion Luis Guillermo Ibarra Ibarra

Armando Odiseo Rodríguez-Olivas

Escuela Nacional de Ciencias Biologicas Departamento de Morfologia

\section{Leonora Casas Ávila}

Instituto Nacional de Rehabilitacion Luis Guillermo Ibarra Ibarra

Margarita Valdés Flores

Instituto Nacional de Rehabilitacion Luis Guillermo Ibarra Ibarra

Elba Reyes Maldonado ( $\nabla$ elbareyesm@gmail.com )

ENCB-IPN: Instituto Politecnico Nacional Escuela Nacional de Ciencias Biologicas https://orcid.org/00000002-4951-6484

\section{Research}

Keywords: Osteonecrosis, Thrombosis, LCPD, COL1A1, COL2A1, MTHFR, CBS, Prothrombin

Posted Date: October 18th, 2021

DOI: https://doi.org/10.21203/rs.3.rs-966812/v1

License: (1) This work is licensed under a Creative Commons Attribution 4.0 International License. Read Full License 


\section{Abstract}

Background: Legg-Calvé-Perthes disease (LCPD) is an avascular osteonecrosis of the femoral epiphysis. It is a rare disease of unclear etiology in children. Alterations in coagulation, or the collagen gene have been described and could be associated with its etiology. Therefore, we set out to evaluate the following alterations: COL1A1 (rs1107946, rs2412298), COL2A1 (rs121912891 and rs387106558), MTHFR rs1801133, CBS rs115742905, and PT rs1799963 and their relationship with LCPD.

Methods: DNA was obtained and genotyped by real-time PCR with TaqMan probes. It was determined prothrombin and homocysteine (Hcy) by a coagulometric method. The variables were described as mean and standard deviation or percentages, and genotypic and allelic distributions were analyzed using the Student's t-test. In addition, the Hardy-Weinberg equilibrium, and OR.

Results: We studied 23 patients with LCPD and 46 controls. We did not find any association of the MTHFR, CBS, PT, COL1A1, and COL2A1 genetic variants with LCPD. However, when adjusting the data with the Hcy values for the MTHFR C677T polymorphism, the $\mathrm{C} / \mathrm{C}$ genotypes showed an association with the recessive model $(p=0.038)$ with susceptibility to LCPD.

Conclusion: No association was found with the CBS, PT, COL1A1, and COL2A1 genes. Nevertheless, our results suggest a significant link between moderately elevated Hcy levels and the MTHFR C677T polymorphism in a cohort of Mexican children with LCPD.

\section{Introduction}

Due to its low prevalence, Legg-Calvé-Perthes disease (LCPD) is rare, particularly in Latin America. It is the avascular osteonecrosis of the femoral head that occurs in the pediatric population [1,2]. The interruption of the blood supply causes fragmentation and deformation of the femoral head, which leads to mechanical alterations in the hip [3]. Although there are several proposed causes, its etiology is still unknown.

Thrombophilia is one of the most widely accepted since the tendency to develop states of hypercoagulability could lead to the development of necrosis [4-6]. On the other hand, described collagen gene alterations could also be associated with the etiology of the disease [7].

The methylenetetrahydrofolate reductase enzyme (MTHFR), together with the Cystathionine $\beta$-synthase (CBS), regulates the serum homocysteine (Hcy) level. MTHFR C677T and CBS T833C polymorphisms, Hcy levels, and other risk factors like polymorphisms of prothrombin G20210A (PT G20210A) have been linked to the development of prothrombotic states [8]. Various studies have suggested that these conditions could be related to the etiology of LCPD $[9,10]$.

LCPD consists of sequential stages of involvement of the femoral epiphyses, including subchondral fracture, fragmentation, reossification, and healing with residual deformity. Genetic factors have been related to the etiology of LCPD, but the causal gene has not been identified. Nonetheless, COL2A1 gene mutations have been implicated in the etiology of LCPD because collagen is the essential matrix protein of all connective 
tissues. Some of these alterations could cause structural defects of type II collagen related to the major clinical aspects $[11,12]$.

On the other hand, the COL1A1 gene encodes the alpha-1 protein chain of type I collagen, the primary protein of bones. Some research focused on the COL1A1 polymorphisms associates them significantly with low bone mineral density, osteoporosis, increased fracture risk, and osteonecrosis $[13,14]$. Also, the deleterious effect of Hcy on bones may be mainly mediated by the binding of the molecule to collagen, which interferes with the formation of type I collagen cross-links [15]. Furthermore, several studies report a significant relationship between hypercoagulability and osteonecrosis [16]. Because of the above, our objective is to evaluate the following alterations involved with coagulation and collagen genes: MTHFR C677T rs1801133, CBS T833C rs115742905, and PT G20210A rs1799963; the following collagen-related polymorphisms: COL1A1 G1997T rs1107946, COL1A1 C1663T rs2412298, COL2A1 G2306A rs121912891, and COL2A1 G3665A rs387106558; and their relationship with LCPD.

\section{Methods}

We carried out a case-control study. All patients were recruited from the Orthopedic Service at Instituto Nacional de Rehabiitación Luis Guillermo Ibarra Ibarra (INR-LGII) in Mexico City. This study included a total of 69 subjects: 23 cases of less than 18 years of age with a clinical and radiological diagnosis of LCPD and 46 healthy controls, matched with the patients 2:1 according to age and gender. In addition, we obtained weight, height, and body mass index (BMI). Patients diagnosed with other bone diseases, diseases related to coagulation abnormalities, and those under pharmacological treatment were excluded to avoid modifying bone metabolism and anticoagulant therapy.

\section{Genotyping}

DNA was obtained from peripheral blood leukocytes. Genotyping was performed by real-time PCR with TaqMan probes in the conditions recommended by the manufacturer (Applied Biosystems, Foster City, CA). Briefly, reactions were performed in $25 \mathrm{ml}$ volume, containing TaqMan PCR master mix (1X), TaqMan probe $(100 \mathrm{~nm})$, primers (900nm of each), and DNA $(25 \mathrm{ng})$. Samples were run in a StepOne Real-Time PCR System (Applied Biosystems). Cycling conditions: one cycle at $95^{\circ} \mathrm{C}$ for $10 \mathrm{~min}$, followed by 40 cycles at $95^{\circ} \mathrm{C}$ for 15 $\mathrm{s}$, and a final cycle at $60^{\circ} \mathrm{C}$ for one min.

\section{Determination of coagulation factor Fll and Hcy}

Plasma was obtained from peripheral blood in tubes with 3.8\% sodium citrate. The hemosiLTM 0020012200 chromogenic kit and the HemosiLTM 0020007800 kit for Hcy were used in ACL-7000 elite pro equipment to determine the prothrombin coagulation factor II (FII). The results were expressed as a percentage of activity for Fll and in $\mu \mathrm{mol} / \mathrm{L}$ for Hcy.

\section{Statistical analysis}

The variables are described as mean \pm standard deviation or as percentages (\%) where appropriate. Differences in genotypic and allelic distribution between case and control groups were analyzed using 
Fisher's exact test or Student's t-test. The Hardy-Weinberg equilibrium (HWE) was calculated for the genotype frequencies in cases and controls using a Chi-square goodness of fit test in SNPStats. The odds ratio (OR) and the confidence interval $(95 \% \mathrm{Cl})$ were calculated to assess the relative risk of having the disease according to the relative frequency of different genotypes between cases and controls with PAST 4.03. Furthermore, the inheritance patterns for SNPs and associations were estimated using SNPStats (http://www.snpstats.net/start.htm).

\section{Ethical aspects}

The cases were patients with LCPD. Controls were selected under the official Mexican standard NOM-253SSA1-2012 guidelines, all participants received oral and written information, and parents or guardians signed a letter of consent. This study was approved by the INR-LGII research and ethics committees.

\section{Results}

23 patients ( 21 men and 2 women) and 46 controls (42 men and 2 women) were recruited. The average height in patients was $1.48 \pm 0.23 \mathrm{~m}$ compared to $1.49 \pm 0.23 \mathrm{~m}$ in controls. The average weight was $46.21 \pm$ $15.02 \mathrm{~kg}$ in patients, compared to $53.83 \pm 24.06 \mathrm{Kg}$ in controls, without significant difference between patients and controls. Similarly, BMI presented no significant differences between patients and controls.

Prothrombin activity did not show a significant difference between the mean of the patients compared to the controls. However, regarding the levels of Hcy, there were significant differences in the mean of the patients in comparison to the controls (Figure 1).

The genotype frequencies of the MTHFR rs1801133 polymorphism were in HWE in controls and patients ( $p=$ 0.76 and $p=0.40$, respectively). The CBS rs115742905 and PT rs1799963 variants are not found in HWE because the mutant allele is absent in either case. The wild genotype resulted in $100 \%$ in both populations (Table 1).

The genotype frequency of the COL1A1 rs1107946 variant was not found in HWE with respect to the controls. No significant differences were observed for the genotype and allelic distribution for the polymorphism between the patients with LCPD and the controls. The COL1A1 variant rs24122948 was found in HWE, but no differences were observed. In the case of COL2A1 rs24122948 and rs106558, we did not find the presence of the mutant alleles (Table 1).

Table 1 presents the link of MTHFR to age, which showed a significant association with the recessive inheritance model.

\section{Discussion}

The prevalence of LCPD is highly variable in different populations. Since it is a rare disease, there are very few reports in Mexico and Latin America that describe it. Children with LCPD begin with pain in one or both legs and a slight limp, usually attributed to falls or poor posture. The pain sometimes goes away temporarily, but the lameness continues. Thus, a long journey of visits to various medical services begins, and it usually 
does not end with a specific diagnosis nor adequate treatment. The correct diagnosis is only given when patients finally go to specialized pediatric orthopedic institutions, such as the INR-LGII. Nevertheless, the number of cases reported in recent years in the INR-LGII is still six to eight cases per year, and each year the number decreases, for the lack of information does not allow an early and specific diagnosis.

The approach to the disease is complicated because its etiology is not yet clear. Genes involved in bone remodeling and architecture have been studied. Furthermore, elevated levels of Hcy have been linked to osteonecrosis [17]. For this reason, we decided to explore variants in the COL1A1 gene that have been studied in relation to osteoporosis and fractures $[18,19]$. However, none of these variants was informative in the studied sample of Mexican patients with LCPD. It has also been suggested that COL2A1, involved in osteonecrosis of the femoral head, is related to skeletal dysplasia due to failure of cartilage development and growth [20]. However, none of these alterations had significant differences between the patients and the controls studied. Additionally, COL2A1 is suggested to be one of the representative causal genes, as Li et al. found a mutation in COL2A1 G1888A in a Chinese family affected by LCPD and osteonecrosis of the femoral head [12,21], and Miyamoto et al. identified a mutation in COL2A1 G3508A in a Japanese family with LCPD. These findings differ from our results since we found no relationship with LCPD [22].

The PT G20210A mutation increases the risk of thrombosis [23]. López et al. studied 90 children with LCPD, and no patient had a family or personal history of early thrombotic events. However, four children with LCPD (4.4\%) were heterozygous for the G20210A polymorphism compared to controls but without any significant association [24]. Vosmaer et al. found an increase in the incidence of LCPD in the presence of the prothrombin mutation when the FVL polymorphism was also present [25]. Our study did not find significant differences that relate this polymorphism, PT rs1799963, with LCPD.

Common alterations in some genes related to Hcy metabolism, such as MTHFR C677T and CBS T833C, have been shown to cause increased plasma homocysteine levels, thus bringing about a predisposition to thrombosis [26]. Our study did not find these variants, CBS T833C rs5742905, neither in controls nor in patients. Azarpira et al. showed that the MTHFR C677T polymorphism was not associated with the risk of LCPD in Iranian children [27]. When we analyzed the results for the MTHFR C677T rs1801133 polymorphism, it did not present a significant association with the risk of susceptibility to LCPD. However, the frequency of the mutant allele was higher than in the Iranian population, even though several epidemiological case-control studies have found that MTHFR polymorphisms could not play a significant role in the susceptibility to the development of osteonecrosis of the femoral head $[28,29]$. In this study, we also found that the levels of Hcy between cases and controls present a significant difference $(p<0.05)$. In addition, when adjusting the value of the MTHFR C677T polymorphism whit age, we found a significant association in the recessive model (OR $5.62(1.02-30.93), p=0.038)$.

In general, hyperhomocysteinemia is a risk factor for various diseases: vascular, neurological, diabetes, psoriasis, cancers, including osteoporosis, among others [30]. In addition, Hcy is thought to alter bone remodeling [31]. Furthermore, it has been described that short-term moderate hyperhomocysteinemia affects bone and cartilage characteristics. Trabecular bone microarchitecture is especially sensitive to hyperhomocysteinemia. It shows clearly negative bone balance, mainly due to a decrease in trabecular 
numbers and markedly reduced trabecular connections, which indicates multiple alterations in collagen due to homocysteine accumulation in bones, indicative of broken collagenous cross-links [32].

\section{Conclusion}

This is the first study to evaluate genetic aspects of coagulation mediators and type I and II collagen in Mexican patients with LCPD. We did not find a relationship of collagen alterations (COL1A1 rs1107946, COL1A1 rs2412298, COL2A1 rs121912891, and COL2A1 rs387106558) or coagulation alterations (CBS T833C rs115742905 and PT G20210A rs1799963) with LCPD. However, we found an association of the MTHFR rs1801133 polymorphism in a recessive model adjusted by age and elevated levels of Hcy in a population of Mexican children with LCPD.

\section{Abbreviations}

LCPD: Legg-Calvé-Perthes disease.

COL1A1: Collagen type I alpha 1 chain.

COL2A1: Collagen type II alpha 1 chain.

MTHFR: methylenetetrahydrofolate reductase.

CBS: cystathionine beta synthase.

PT: Prothrombin.

DNA: Deoxyribonucleic acid.

Hcy: Homocysteine.

INR-LGII: Instituto Nacional de Rehabilitación "Luis Guillermo Ibarra Ibarra".

BMI: Body mass index.

FII: Coagulation factor II.

HWE: Hardy-Weinberg equilibrium.

OR: Odds ratio.

Cl: Confidence interval.

SNPs: Single nucleotide polymorphisms.

NOM: Norma Oficial Mexicana.

\section{Declarations}


Acknowledgments

Thanks to reviewer Alejandra Tapia Alcazar for her assistance in the preparation of this manuscript.

In loving memory of M.D. Antonio Redón Tavera, head of the Pediatric Hip Service, INR-LGII.

\section{Funding}

This study had no specific funding.

\section{Contributions}

EHZ, AORO, and ERM conceived and designed the experiments. JGBP, LCA, MVF, AORO and EHZ collected blood samples and clinical data. JGBP and AORO performed the experiments. EHZ, AORO, JGBP and ERM wrote the paper. All authors read and approved the final manuscript.

\section{Ethics declarations}

All participants received oral and written information about the study and signed a letter of consent. The study protocol was reviewed and approved by the INR-LGII Research and Ethics Committees.

\section{Consent for publication}

All authors consent to publish.

\section{Competing interests}

The authors declare that they have no competing interests.

\section{Availability of data and materials}

All relevant data used in this study have been included in the manuscript. The corresponding author can be contacted if any further information is needed.

\section{References}

1. Jaramillo D (2009) What is the optimal imaging of osteonecrosis, Perthes, and bone infarcts? Pediatric radiology 39:216.

2. Srzentić S, Nikčević G, Spasovski D, Baščarević Z, Živković Z, Terzic-Šupić Z, Matanović D, Djordjević V, Pavlović S, Spasovski V (2015) Predictive genetic markers of coagulation, inflammation, and apoptosis in Perthes disease-Serbian experience. European journal of pediatrics 174:1085-92.

3. Chen L, Hong G, Zhang Q, Chen Z, Fang B, He W (2017) Waldenström classification: better evaluation for the intervention time of Scottish rite brace treatment in Legg-Calvé-Perthes disease. Int J Clin Exp Med 10:724-31.

4. Kealey WD, Mayne EE, McDonald W, Murray P, Cosgrove AP (2000) The role of coagulation abnormalities in the development of Perthes' disease. J Bone Joint Surg Br 82:744-6. 
5. Arruda VR, Belangero WD, Ozelo MC, Oliveira GB, Pagnano RG, Volpon JB, Annichino-Bizzacchi JM (1999) Inherited risk factors for thrombophilia among children with Legg-Calvé-Perthes disease. J Pediatr Orthop19:84-7.

6. Perry DC, Hall AJ (2011) The epidemiology and etiology of Perthes disease. Orthop Clin North Am 42:279-83,

7. Poort SR, Rosendaal FR, Reitsma PH, Bertina RM (1996) A common genetic variation in the 3'untranslated region of the prothrombin gene is associated with elevated plasma prothrombin levels and an increase in venous thrombosis. Blood 88:3698-703.

8. Zavala-Hernández C, Hernández-Zamora E, Martínez-Murillo C, Majluf-Cruz A, Vela-Ojeda J, GarcíaChávez J, Reyes-Maldonado E. (2015) Risk Factors for Thrombosis Development in Mexican Patients. Ann Vasc Surg 29:1625-32.

9. Loder RT, Skopelja EN (2011) The epidemiology and demographics of Legg-Calvé-Perthes disease. ISRN Orthop 504393.

10. Chaudhry S, Phillips D, Feldman D. Legg-Calvé-Perthes disease: an overview with recent literature (2014) Bull Hosp Jt Dis 72(1):18-27.

11. Kannu P, Bateman J, Savarirayan R (2012) Clinical phenotypes associated with type II collagen mutations. J Paediatr Child Health 48: E38-43.

12. Li N, Yu J, Cao X, Wu QY, Li WW, Li TF, Zhang C, Cui YX, Li XJ, Yin ZM, Xia XY (2014) A novel p. Gly630Ser mutation of COL2A1 in a Chinese family with presentations of Legg-Calve-Perthes disease or avascular necrosis of the femoral head. PLoS One 9:e100505.

13. Urreizti R, Garcia-Giralt N, Riancho JA, González-Macías J, Civit S, Güerri R, Yoskovitz G, Sarrion P, Mellivobsky L, Díez-Pérez A, Nogués X, Balcells S, Grinberg D (2012) COL1A1 haplotypes and hip fracture. J Bone Miner Res 27:950-3.

14. Erdem M, Tüfekçi Ö, Kızıldağ S, Yılmaz Ş, Kızmazoğlu D, Eroğlu Filibeli B, Ören H (2019) Investigation of the Relationship Between Fok1 and Col1A1 Gene Polymorphisms and Development of TreatmentRelated Bone Complications in Children with Acute Lymphoblastic Leukemia. Turk J Haematol 36:12-18.

15. Jackson SH (1973) The reaction of homocysteine with aldehyde: an explanation of the collagen defects in homocystinuria. Clin Chim Acta 45:215-7

16. Azarpira MR, Ghilian MM, Sobhan MR, Mehdinezhad-Yazdi M, Aghili K, Miresmaeili SM, Neamatzadeh H (2018) Association of MTHFR and TNF-a genes polymorphisms with susceptibility to Legg-CalvePerthes disease in Iranian children: A case-control study. J Orthop 15:984-987.

17. Glueck CJ, Freiberg RA, Fontaine RN, Tracy T, Wang P (2001) Hypofibrinolysis, thrombophilia, osteonecrosis. Clin Orthop Relat Res 386:19-33.

18. Moradifard S, Hoseinbeyki M, Emam MM, Parchiniparchin F, Ebrahimi-Rad M. (2020) Association of the Sp1 binding site and -1997 promoter variations in COL1A1 with osteoporosis risk: The application of meta-analysis and bioinformatics approaches offers a new perspective for future research. Mutat Res786:108339.

19. Jin H, Evangelou E, loannidis JP, Ralston SH. (2011) Polymorphisms in the 5' flank of COL1A1 gene and osteoporosis: meta-analysis of published studies. Osteoporos Int. 22:911-21. 
20. Sakamoto Y, Yamamoto T, Miyake N, Matsumoto N, lida A, Nakashima Y; Research Committee on Idiopathic Osteonecrosis of the Femoral Head of the Ministry of Health, Labour and Welfare of Japan, Iwamoto Y, Ikegawa S (2017) Screening of the COL2A1 mutation in idiopathic osteonecrosis of the femoral head. J Orthop Res 35:768-774.

21. Al-Omran AK, Sadat-Ali M (2013) Legg-Calvé-Perthes disease in two generations of male family members: a case report. J Orthop Surg (Hong Kong) 21:258-61.

22. Miyamoto $Y$, Matsuda T, Kitoh H, Haga N, Ohashi H, Nishimura G, Ikegawa S (2007) A recurrent mutation in type II collagen gene causes Legg-Calvé-Perthes disease in a Japanese family. Hum Genet 121:625-9.

23. Carter AM, Sachchithananthan M, Stasinopoulos S, Maurer F, Medcalf RL (2002) Prothrombin G20210A is a bifunctional gene polymorphism. Thromb Haemost 87:846-53.

24. López-Franco M, González-Morán G, De Lucas JC Jr, Llamas P, de Velasco JF, Vivancos JC, EpeldeguiTorre T (2005) Legg-perthes disease and heritable thrombophilia. J Pediatr Orthop 25:456-9.

25. Vosmaer A, Pereira RR, Koenderman JS, Rosendaal FR, Cannegieter SC (2010) Coagulation abnormalities in Legg-Calvé-Perthes disease. J Bone Joint Surg Am 92:121-8.

26. Akar N, Akar E, Misirlioğlu M, Avcu F, Yalçin A, Cin S (1998) Search for genetic factors favoring thrombosis in Turkish population. Thromb Res 92:79-82.

27. Azarpira MR, Ghilian MM, Sobhan MR, Mahdinezhad-Yazdi M, Aghili K, Ahrar H, Neamatzadeh H (2019) Association of eNOS 27-bp VNTR, 894G $>$ T and 786T $>$ C polymorphisms with susceptibility to LeggCalve-Perthes Disease in Iranian children. J Orthop16:137-140.

28. Chai W, Zhang Z, Ni M, Geng P, Lian Z, Zhang G, Shi LL, Chen J (2015) Genetic association between methylenetetrahydrofolate reductase gene polymorphism and risk of osteonecrosis of the femoral head. Biomed Res Int 2015:196495.

29. Kim TH, Hong JM, Kim HJ, Park EK, Kim SY (2010) Lack of association of MTHFR gene polymorphisms with the risk of osteonecrosis of the femoral head in a Korean population. Mol Cells 29:343-8.

30. Liew SC, Gupta ED. Methylenetetrahydrofolate reductase (MTHFR) C677T polymorphism: epidemiology, metabolism and the associated diseases. Eur J Med Genet 2015;58(1):1-10.

31. Vacek TP, Kalani A, Voor MJ, Tyagi SC, Tyagi N. The role of homocysteine in bone remodeling. Clin Chem Lab Med 2013;51(3):579-90.

32. Milovanovic P, Hrncic D, Radotic K, Stankovic M, Mutavdzic D, Djonic D, Rasic-Markovic A, Djuric D, Stanojlovic 0 , Djuric M. Moderate hyperhomocysteinemia induced by short-term dietary methionine overload alters bone microarchitecture and collagen features during growth. Life Sci 2017; 191:9-16.

\section{Tables}


Table 1. Association of MTHFR rs1801133, CBS rs115742905, PT rs1799963, COL1A1 rs1107946 and rs2412298, COL2A1 rs121912891 and rs387906558 with Legg-Calvé-Perthes Disease

$\begin{array}{lllllll}\text { SNP and } & \text { Genotype } & \text { Controls } & \text { Cases } & \text { OR }(95 \% \mathrm{Cl}) & \mathrm{p} \text { - } \\ \text { Model } & & \mathrm{n}(\%) & \mathrm{n}(\%) & & \text { value }(95 \% \mathrm{Cl}) * & \begin{array}{c}\mathrm{p}- \\ \text { value } \\ *\end{array}\end{array}$

\section{MTHFR}

rs1801133

\begin{tabular}{|c|c|c|c|c|c|c|c|}
\hline & $\mathrm{T} / \mathrm{T}$ & $\begin{array}{l}15 \\
(32.6 \%)\end{array}$ & $\begin{array}{l}6 \\
(26.1 \%)\end{array}$ & 1.00 & & 1.00 & \\
\hline \multirow[t]{2}{*}{ Codominant } & $\mathrm{C} / \mathrm{T}$ & $\begin{array}{l}21 \\
(45.6 \%)\end{array}$ & $\begin{array}{l}9 \\
(39.1 \%)\end{array}$ & $\begin{array}{l}1.07(0.31- \\
3.66)\end{array}$ & & $\begin{array}{l}0.43(0.08- \\
2.30)\end{array}$ & \\
\hline & $\mathrm{C} / \mathrm{C}$ & $\begin{array}{l}10 \\
(21.7 \%)\end{array}$ & $\begin{array}{l}8 \\
(34.8 \%)\end{array}$ & $\begin{array}{l}2.00(0.53- \\
7.54)\end{array}$ & 0.51 & $\begin{array}{l}3.69(0.56- \\
24.56)\end{array}$ & 0.07 \\
\hline \multirow[t]{2}{*}{ Dominant } & $\mathrm{T} / \mathrm{T}$ & $\begin{array}{l}15 \\
(32.6 \%)\end{array}$ & $\begin{array}{l}6 \\
(26.1 \%)\end{array}$ & 1.00 & & 1.00 & \\
\hline & $\mathrm{C} / \mathrm{T}-\mathrm{C} / \mathrm{C}$ & $\begin{array}{l}31 \\
(67.4 \%)\end{array}$ & $\begin{array}{l}17 \\
(73.9 \%)\end{array}$ & $\begin{array}{l}1.37(0.45- \\
4.19)\end{array}$ & 0.58 & $\begin{array}{l}0.97(0.23- \\
3.99)\end{array}$ & 0.96 \\
\hline \multirow[t]{2}{*}{ Recessive } & $\mathrm{T} / \mathrm{T}-\mathrm{C} / \mathrm{T}$ & $\begin{array}{l}36 \\
(78.3 \%)\end{array}$ & $\begin{array}{l}15 \\
(65.2 \%)\end{array}$ & 1.00 & & 1.00 & \\
\hline & $\mathrm{C} / \mathrm{C}$ & $\begin{array}{l}10 \\
(21.7 \%)\end{array}$ & $\begin{array}{l}8 \\
(34.8 \%)\end{array}$ & $\begin{array}{l}1.92(0.63- \\
5.81)\end{array}$ & 0.25 & $\begin{array}{l}5.62(1.02- \\
30.93)\end{array}$ & 0.038 \\
\hline
\end{tabular}

\section{CBS}

rs115742905

\begin{tabular}{llllll} 
& T/T & $\begin{array}{l}46 \\
(100.0 \%)\end{array}$ & $\begin{array}{l}23 \\
(100.0 \%)\end{array}$ & $\begin{array}{l}\text { Monomorphic } \\
\text { SNP }\end{array}$ & $\begin{array}{l}\text { Monomorphic } \\
\text { SNP }\end{array}$ \\
\hline & T/C & $0(0.0 \%)$ & $0(0.0 \%)$ & & \\
\hline C/C & $0(0.0 \%)$ & $0(0.0 \%)$ & \\
\hline
\end{tabular}

\section{PT}

rs1799963

\begin{tabular}{|c|c|c|c|c|c|}
\hline & $\mathrm{G} / \mathrm{G}$ & $\begin{array}{l}46 \\
(100.0 \%)\end{array}$ & $\begin{array}{l}23 \\
(100.0 \%)\end{array}$ & & \\
\hline-1 & $\mathrm{G} / \mathrm{A}$ & $0(0.0 \%)$ & $0(0.0 \%)$ & $\begin{array}{l}\text { Monomorphic } \\
\text { SNP }\end{array}$ & $\begin{array}{l}\text { Monomorphic } \\
\text { SNP }\end{array}$ \\
\hline & $\mathrm{A} / \mathrm{A}$ & $0(0.0 \%)$ & $0(0.0 \%)$ & & \\
\hline
\end{tabular}

G/G 
$(45.6 \%) \quad(56.5 \%)$

$\begin{array}{llllllll}\text { Codominant } & \mathrm{G} / \mathrm{T} & 13 & 6 & 0.75(0.23- & 0.63 & 0.73(0.22- & \\ & & (28.3 \%) & (26.1 \%) & 2.45) & & 2.42) & \\ & \mathrm{T} / \mathrm{T} & 12 & 4 & 0.54(0.14- & & 0.53(0.14- & 0.62 \\ & & ((26.1 \%) & (17.4 \%) & 2.03) & & 2.00) & \end{array}$

$\begin{array}{llllllll}\text { Dominant } & \text { G/G } & \begin{array}{l}21 \\ (45.6 \%)\end{array} & \begin{array}{l}13 \\ (56.51 \%)\end{array} & 1.00 & & 1.00 \\ & \text { G/T-T/T } & \begin{array}{l}25 \\ (54.4 \%)\end{array} & \begin{array}{l}10 \\ (43.5 \%)\end{array} & \begin{array}{l}0.60(0.17- \\ 2.11)\end{array} & 0.41 & 0.63(0.23- & 0.38 \\ & & & & & & \\ & & & & & \\ \text { Recessive } & \text { G/G-G/T } & 34 & 19 & 1.00 & 1.00 & \\ & & (73.9 \%) & (82.6 \%) & & & & \\ & \text { T/T } & 12 & 4 & 0.60(0.17- & 0.41 & 0.59(0.17- & 0.41 \\ & & (26.1 \%) & (17.4 \%) & 2.11) & & 2.10) & \end{array}$

COL1A1

rs2412298

\begin{tabular}{llllllll}
\hline & $\mathrm{C} / \mathrm{C}$ & 39 & 19 & 1.00 & & 1.00 & \\
& & $(84.8 \%)$ & $(82.6 \%)$ & & & & \\
\hline & $\mathrm{C} / \mathrm{T}$ & 7 & 4 & $1.17(0.31-$ & 0.82 & $1.18(0.31-$ & 0.81 \\
& & $(15.2 \%)$ & $(17.4 \%)$ & $4.50)$ & & $4.55)$ & \\
\hline
\end{tabular}

\section{COL2A1}

rs121912891

\begin{tabular}{llllll} 
& G/G & $\begin{array}{l}46 \\
(100.0 \%)\end{array}$ & $\begin{array}{l}23 \\
(100.0 \%)\end{array}$ & $\begin{array}{l}\text { Monomorphic } \\
\text { SNP }\end{array}$ & $\begin{array}{l}\text { Monomorphic } \\
\text { SNP }\end{array}$ \\
\hline & G/A & $0(0.0 \%)$ & $0(0.0 \%)$ & & \\
\hline & A/A & $0(0.0 \%)$ & $0(0.0 \%)$ &
\end{tabular}

\section{COL2A1}

rs387906558

\begin{tabular}{|c|c|c|c|c|c|}
\hline & $\mathrm{G} / \mathrm{G}$ & $\begin{array}{l}46 \\
(100.0 \%)\end{array}$ & $\begin{array}{l}23 \\
(100.0 \%)\end{array}$ & $\begin{array}{l}\text { Monomorphic } \\
\text { SNP }\end{array}$ & $\begin{array}{l}\text { Monomorphic } \\
\text { SNP }\end{array}$ \\
\hline 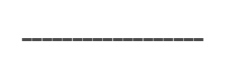 & $\mathrm{G} / \mathrm{A}$ & $0(0.0 \%)$ & $0(0.0 \%)$ & & \\
\hline & $\mathrm{A} / \mathrm{A}$ & $0(0.0 \%)$ & $0(0.0 \%)$ & & \\
\hline
\end{tabular}

\# Raw data; * Adjusted by age; Significant values are shown in bold.

\section{Figures}


A)

FII

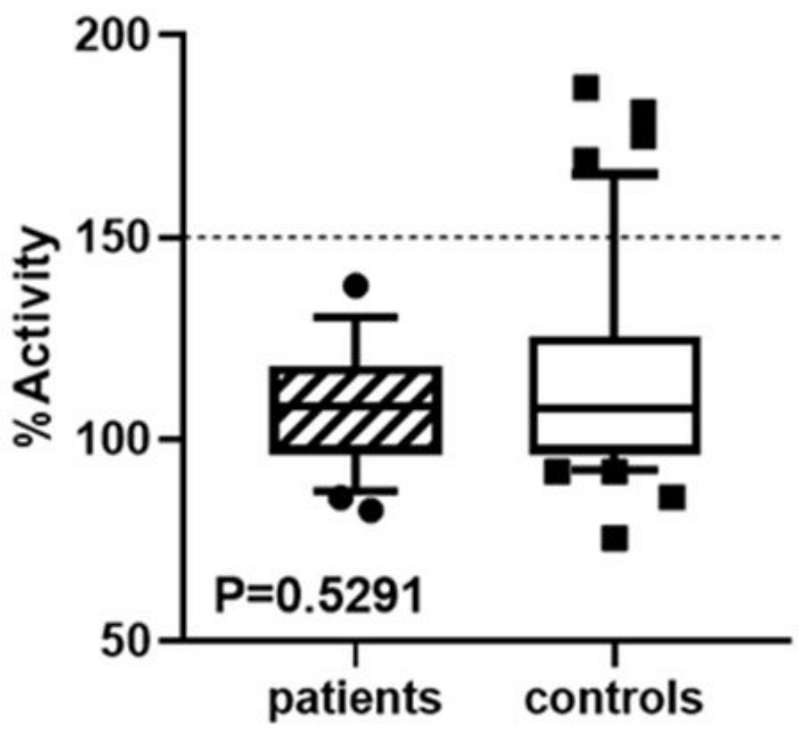

B)

Homocysteine

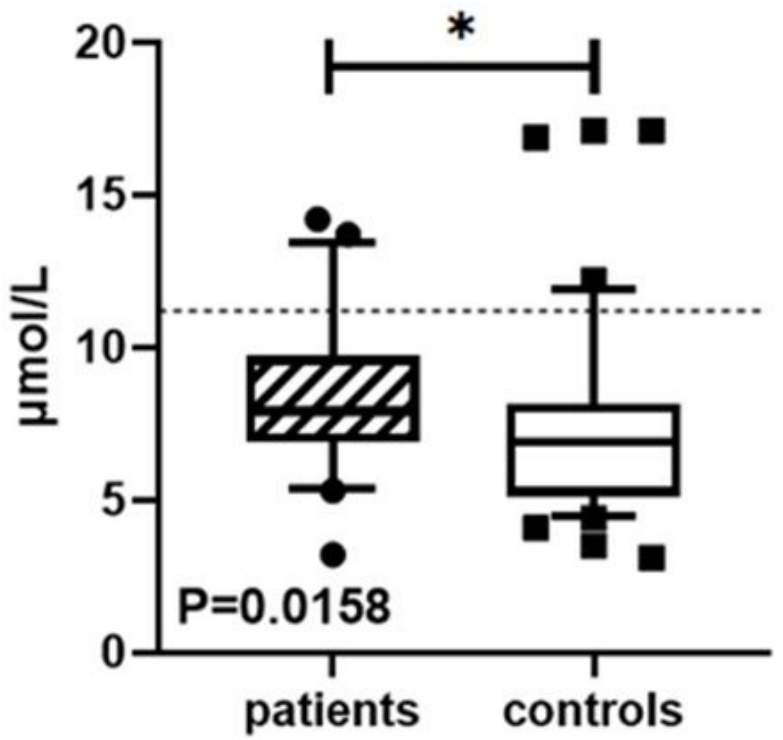

Figure 1

Comparison of A) Factor II (prothrombin) and B) Homocysteine. Mustache graphs showing the median and the 10-90 percentile. Out-of-range values $(\because, \cdots, \mathbf{\square}, \mathbf{\square}$, outliers) are represented with dots outside the mentioned percentiles. The p-value from the comparison between patients and controls is also shown. Compared samples that showed a significant difference according to the Mann-Whitney U-test are highlighted with an asterisk $\left({ }^{\star}\right)$, dotted line= maximum proposed reference value for children $(\cdots \cdot)$. 